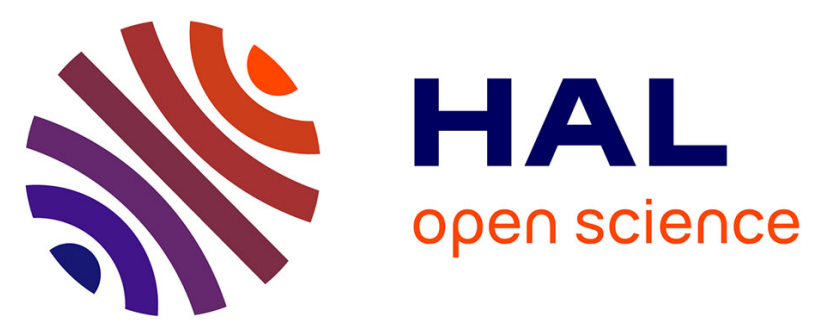

\title{
Circulating microRNAs after a 24-h ultramarathon run in relation to muscle damage markers in elite athletes
} Emeric Chalchat, Keyne Charlot, Sebastian Garcia-vicencio, Pierre Hertert, Stéphane Baugé, Stéphanie Bourdon, Julie Bompard, Cédric Farges, Martin Vincent, Cyprien Bourrilhon, et al.

\section{To cite this version:}

Emeric Chalchat, Keyne Charlot, Sebastian Garcia-vicencio, Pierre Hertert, Stéphane Baugé, et al.. Circulating microRNAs after a 24-h ultramarathon run in relation to muscle damage markers in elite athletes. Scandinavian Journal of Medicine and Science in Sports, inPress, 31 (9), pp.1782-1795. 10.1111/sms.14000 . hal-03252968

\section{HAL Id: hal-03252968 https://hal.science/hal-03252968}

Submitted on 8 Jun 2021

HAL is a multi-disciplinary open access archive for the deposit and dissemination of scientific research documents, whether they are published or not. The documents may come from teaching and research institutions in France or abroad, or from public or private research centers.
L'archive ouverte pluridisciplinaire HAL, est destinée au dépôt et à la diffusion de documents scientifiques de niveau recherche, publiés ou non, émanant des établissements d'enseignement et de recherche français ou étrangers, des laboratoires publics ou privés. 


\section{Article type : Original Article}

\section{Circulating microRNAs after a 24-h ultramarathon run in relation to muscle damage markers in elite athletes}

Emeric Chalchat ${ }^{1,2}$, Keyne Charlot ${ }^{1,3}$, Sebastian Garcia-Vicencio ${ }^{1,3}$, Pierre Hertert ${ }^{4}$, Stéphane Baugé ${ }^{1,3}$, Stéphanie Bourdon ${ }^{1,3}$, Julie Bompard ${ }^{5}$, Cédric Farges ${ }^{6}$, Vincent Martin², 7, Cyprien Bourrilhon $^{1,3,4 \$}$, and Julien Siracusa ${ }^{1,3 \$ *}$

\$These authors contributed equally to this work

${ }^{1}$ Institut de Recherche Biomédicale des Armées, Unité de Physiologie des Exercices et Activités en Conditions Extrêmes, Département Environnements Opérationnels, 91223 Bretigny-Sur-Orge, France

${ }^{2}$ Université Clermont Auvergne, AME2P, F-63000, Clermont-Ferrand, France

${ }^{3}$ LBEPS, Univ Evry, IRBA, Université Paris Saclay, 91025 Evry, France

${ }^{4}$ Fédération française d'athlétisme, 75640 Paris Cedex, France

${ }^{5}$ Hôpital d'Instruction des Armées Percy, 92140 Clamart, France

${ }^{6}$ Centre Hospitalier d'Albi, 81000 Albi, France

${ }^{7}$ Institut Universitaire de France (IUF), Paris, France

This article has been accepted for publication and undergone full peer review but has not been through the copyediting, typesetting, pagination and proofreading process, which may lead to differences between this version and the Version of Record. Please cite this article as doi: 10.1111/SMS.14000

This article is protected by copyright. All rights reserved 


\section{*Corresponding author}

Julien Siracusa, $\mathrm{PhD}$

Institut de Recherche Biomédicale des Armées,

1 place du général Valérie André,

91223 Bretigny-Sur-Orge

France

Phone: + 33 (0)178651302

Fax: +33 (0)178651643

E-mail: siracusa.julien@gmail.com 


\section{Abstract}

Ultra-endurance sports are growing in popularity but can be associated with adverse health effects; such as exercise-induced muscle damage (EIMD), which can lead to exertional rhabdomyolysis. Circulating microRNAs (miRNAs) may be useful to approach the degree of EIMD. We aimed to: 1) investigate the relevance of circulating miRNAs as biomarkers of muscle damage and 2) examine the acute response of skeletal/cardiac muscle and kidney biomarkers to a 24-h run in elite athletes. Eleven elite athletes participated in the 24-h Run World Championships. Countermovement jump (CMJ), creatine kinase $(\mathrm{CK})$, myoglobin $(\mathrm{Mb})$, creatinine $(\mathrm{Cr})$, high-sensitive cardiac troponin $\mathrm{T}$ (hs-cTnT) and muscle-specific miRNA (myomiR) levels were measured before, immediately after, and 24 and $48 \mathrm{~h}$ after the race. CMJ height was reduced immediately after the race $(-84.0 \pm 25.2 \%, \mathrm{p}<0.001)$ and remained low at $24 \mathrm{~h}(-43.6 \pm 20.4 \%, \mathrm{p}=0.002)$. We observed high CK activity $(53,239 \pm 63,608 \mathrm{U} / \mathrm{L}, \mathrm{p}<0.001)$ immediately after the race and it remained elevated $24 \mathrm{~h}$ after $(\mathrm{p}<0.01)$. Circulating myomiRs levels $(\mathrm{miR}-1-3 \mathrm{p}$, miR-133a-3p, miR133b, miR-208a-3p, miR-208b-3p, and miR-499a-5p) were elevated immediately after the 24-h run (fold changes: $18-124,723, p<0.001)$ and significantly $(\mathrm{p}<0.05)$ correlated or tended to significantly $(\mathrm{p}<0.07)$ correlate with the reduction in CMJ height at $24 \mathrm{~h}$. We found no significant correlation between CMJ height loss at $24 \mathrm{~h}$ and $\mathrm{CK}(\mathrm{p}=0.23)$ or $\mathrm{Mb}(\mathrm{p}=0.41)$ values. All elite ultramarathon runners included in our study were diagnosed with exertional rhabdomyolysis after the 24-h ultramarathon race. MyomiR levels may be useful to approach the degree of muscle damage.

Keywords: exercise-induced muscle damage, rhabdomyolysis, ultra-endurance, muscle function, cardiac stress, acute kidney injury, biomarkers. 


\section{Introduction}

Ultra-endurance and ultramarathon events $(>42.195 \mathrm{~km})$ have experienced considerable growth in recent years. Their growing popularity, along with the constant pursuit of overcoming one's limitations, has given rise to extremely challenging sports events. A $24-\mathrm{h}$ run is a form of ultramarathon in which a competitor runs as far as possible in $24 \mathrm{~h}$ on a short loop $(400-2,500$ $\mathrm{m})$. The current World records are $303.5 \mathrm{~km}$ for men and $270.1 \mathrm{~km}$ for women, corresponding to mean running speeds of $\sim 12.6$ and $\sim 11.3 \mathrm{~km} / \mathrm{h}$, respectively. To achieve a good performance, athletes must efficiently manage their exercise work rate by adopting a pacing strategy ${ }^{1}$ and managing their energy and fluid intake ${ }^{2}$. On the other hand, the extreme duration and high number of stretch-shortening cycles performed by exercising muscles over the 24 -h race result in a high level of exercise-induced muscle fatigue and damage, which translates into an acute reduction in performance ${ }^{3}$.

The evidence that strenuous ultra-endurance exercise can cause alterations in metabolism 4 and the cardiovascular ${ }^{5}$ and musculoskeletal systems ${ }^{3}$ is well established. Prior studies have shown that prolonged exercise, such as that encountered in ultra-endurance events, is associated with cardiac stress ${ }^{6}$, exertional rhabdomyolysis, and sometimes acute kidney injury ${ }^{7}$. Exertional rhabdomyolysis can manifest as myalgia, weakness, and edema and is characterized by muscle breakdown and necrosis, resulting in leakage of intracellular muscle constituents, such as electrolytes and sarcoplasmic proteins, including myoglobin $(\mathrm{Mb})$ and creatine kinase $(\mathrm{CK})$, into circulation and the extracellular space. The accumulation of sarcoplasmic proteins, specifically myoglobin, in the circulation is a potential complication for the kidneys ${ }^{8}$. Acute kidney injury is a final-stage complication of massive rhabdomyolysis and is defined as a rapid decline in renal functionality (hours to days) ${ }^{9}$. Although the impact of ultra-endurance exercise on cardiac damage biomarkers and the risk of exertional rhabdomyolysis and acute kidney injury has been largely evaluated ${ }^{7}$, it is known that training status can affect the markers of muscle damage after exerciseinduced muscle damage (EIMD) ${ }^{10}$. However, the effect of ultra-endurance racing on elite runners is still poorly documented.

Although delayed loss of muscle function (i.e. 24-48 h) is considered to be the best indirect marker for evaluating the magnitude of exercise-induced muscle damage ${ }^{11}$, early measurement (i.e. within a few hours after the end of exercise) may reflect a combination of muscle damage and muscle fatigue rather than muscle damage alone ${ }^{11,12}$. This marker is therefore not suitable in 
clinical practice due to the necessity of immediate diagnosis of muscle damage. Indeed, rapid countermeasures are required to prevent the risk of exertional rhabdomyolysis and acute kidney injury. Serum $\mathrm{CK}$ and $\mathrm{Mb}$ levels are the most commonly used biomarkers of exertional rhabdomyolysis ${ }^{13}$ but there is no accepted cut-off threshold for these biomarkers (CK: $5-10 \mathrm{X}$ the upper limit range or $>5,000-10,000 \mathrm{U} / \mathrm{L}, \mathrm{Mb}: 400-4000 \mathrm{ng} / \mathrm{mL})^{14,15}$. Indeed, the interpretation of these biomarkers is affected by high interindividual variability and does not necessarily reflect the magnitude of delayed loss of muscle function ${ }^{16}$. Moreover, there are currently no markers considered to be a "gold standard" for the evaluation of the degree of exertional rhabdomyolysis ${ }^{17}$. It is therefore necessary to search for new relevant biomarkers that increase within the first hours after exercise and accurately predict the magnitude of muscle damage.

MicroRNAs (miRNAs), small noncoding RNA involved in the post-transcriptional regulation of gene expression, may potentially serve as alternative biomarkers of muscle damage $^{18,19}$. Indeed, some miRNAs (miR-1, -133a, -133b, -206, -208a, -208b, -486, and -499) have been described as muscle-specific/enriched (cardiac and skeletal muscle), two of which are specifically found in skeletal muscle (miR-133b and -206) and one in the cardiac muscle (miR$208 \mathrm{a})^{20}$. These specific/enriched miRNAs (also called myomiRs) can be actively secreted by or passively leak out of injured myocytes and measured in the blood. High levels of serum/plasma myomiRs have been found in muscular dystrophy and myocardial infarction (MI) patients relative to healthy subjects ${ }^{21,22}$. In the healthy organism, elevation of myomiR has been observed after toxic muscle injury in rats $^{20}$ and after marathon running ${ }^{19}$. Moreover, it has been reported that the ability of myomiR to discriminate damaged from nondamaged muscle is higher than that of $\mathrm{CK}^{18,20}$, suggesting that myomiR may more accurately diagnose muscle damage. Although no study has investigated the relationship between myomiR levels and skeletal muscle function, Corsten et al. ${ }^{23}$ found a good correlation between miR-499 and troponin T levels in MI patients suggesting that this miRNA could be useful for determining the degree of muscle damage.

Here, we aimed to: 1) investigate the relevance of circulating miRNA as biomarkers of muscle damage and 2) examine the acute response of skeletal/cardiac muscle and kidney biomarkers to the 24-h run World Championships in elite athletes. We hypothesized that the present athletes would be diagnosed with exertional rhabdomyolysis, acute kidney injury and present cardiac stress in response to the 24-h run. Moreover, myomiR levels would be more representative of muscle damage than those of $\mathrm{CK}$ and $\mathrm{Mb}$ (i.e. more associated with muscle function loss at $24 \mathrm{~h}$ ). 


\section{Methods}

\section{Participants}

Athletes of the French national team (5 men and 6 women) gave their written informed consent and agreed to participate in this study. The participant's characteristics are provided on table 1. The study was conducted in accordance with the Declaration of Helsinki and was approved by the Regional Ethics Committee (CPP Ile-de-France 8, France, registration number: 2019-A02445-52, Etude LemuR).

\section{Experimental design}

This study was conducted during the 2019 IAU 24H World Championships held in Albi (France) from October 26-27, 2019. The race consisted of running the greatest distance possible over $24 \mathrm{~h}$ (start of the race at 10:00 am the first day) on a loop of $1.491 \mathrm{~km}$ combining asphalt $(\sim 75 \%)$ and tartan track ( 25\%; see Figure 1$)$.

Vertical jump height (as an indicator of muscle function) and muscle soreness were assessed $26 \mathrm{~h}$ before (between 7:00 am and 9:00 am, PRE), within $1 \mathrm{~h}$ after finishing (POST), and 24 and $48 \mathrm{~h}$ after the race. Blood samples were obtained at the same time points for biological analysis. A blood test was completed each morning in a fasted state. Dietary intakes were recorded during the race (Lavoué et al. ${ }^{2}$ ). As the medical staff did not permit some participants to performed CMJ due to medical monitoring, one participant (POST), two participants $(+24)$ and four participants $(+48)$ did not perform the CMJ. Participants were asked to refrain performing any physical activity the two days after the race.

\section{Functional measurements}

\section{Vertical jump}

Counter-movement jump (CMJ) height was assessed using an Optojump photocell system (Microgate, Bolzano, Italy), and used as a measure of muscle function. Participants were asked to keep their hands on their hips and jump as high as possible. They had two attempts to achieve their best maximal jump height, which was used for further analysis. A self-determined range of motion for the knee was permitted and they received verbal encouragement.

\section{Muscle soreness}


The magnitude of muscle soreness of the quadriceps was assessed using a visual analog scale, consisting of a 100-mm line representing "no pain" at one end $(0 \mathrm{~mm})$, and "very, very painful" at the other $(100 \mathrm{~mm})$, while performing a squat in $90^{\circ}$ knee range of motion. Due to severe range of motion limitation observed immediately after the end of the race, the participants performed a squat on a self-determined range motion, i.e. as flexed as possible.

\section{Biological measurements}

\section{Sampling}

Blood was drawn from the antecubital vein at each time point and collected into two separate tubes ( $5 \mathrm{~mL}$, Becton Dickinson Vacutainer, Franklin Lakes, USA), one containing EDTA and the other lithium heparin. The collected blood was conserved at $4{ }^{\circ} \mathrm{C}$ until plasma was separated by centrifugation $(2,000 \mathrm{x} g, 10 \mathrm{~min})$ within $1 \mathrm{~h}$ of collection. Lithium heparin plasma was used within $2 \mathrm{~h}$ for standard biochemical analyses and EDTA plasma was aliquoted and frozen at $-20^{\circ} \mathrm{C}$ for further analyses.

\section{Biochemical analyses}

Plasma CK activity and $\mathrm{Mb}$ concentration were measured using a Roche Cobas c501 autoanalyzer and high-sensitive cardiac troponin $\mathrm{T}$ (hs-cTnT) and creatinine $(\mathrm{Cr})$ concentrations using a Roche Cobas e501/e601 autoanalyzer (Roche Diagnostics GmbH, Mannheim, Germany). The estimated glomerular filtration rate (eGFR) was calculated using the CKD-EPI (CKD Epidemiology Collaboration) equation. Before the race, several participants presented $\mathrm{Mb}$ and hscTnT values below the detection limit of $21 \mathrm{ng} / \mathrm{mL}$ (5 of $11 \mathrm{PRE}$ values) and $5 \mathrm{ng} / \mathrm{L}$ (8 of 11), respectively. For statistical analysis, such samples were given the value of the detection limit.

\section{Plasma miRNA extraction}

Total RNA was extracted from plasma as previously described ${ }^{18,20}$. Briefly, total RNA was extracted from $200 \mu \mathrm{L}$ plasma using the mirVana PARIS kit (Ambion, Austin, USA) and lowbinding tubes (1.5 mL, DNA LoBind Tubes, Eppendorf, hamburg, Germany) according to the manufacturer's protocol. An additional precipitation step was performed as follows. Column elution was performed with $180 \mu \mathrm{L}$ sterile water. Then, $18 \mu \mathrm{L} 3 \mathrm{M}$ sodium acetate (Sigma-Aldrich, Saint-Quentin-Fallavier, France), $400 \mu \mathrm{L} 70 \%$ ethanol, and $1 \mu \mathrm{L}$ GlycoBlue (Ambion) were added. Tubes were vortexed and the RNA allowed to precipitate for $20 \mathrm{~min}$ at $-20^{\circ} \mathrm{C}$. After centrifugation $\left(12,000 \mathrm{x} \mathrm{g}, 4^{\circ} \mathrm{C}, 10 \mathrm{~min}\right)$, the supernatants were carefully removed and the pellets 
allowed to dry for $30 \mathrm{~min}$. The RNA was finally suspended in $12 \mu \mathrm{L}$ sterile water, incubated 10 min at $50^{\circ} \mathrm{C}$, and frozen at $-80^{\circ} \mathrm{C}$ until cDNA synthesis.

\section{Reverse transcription}

cDNAs were synthesized from $5 \mu \mathrm{L}$ total RNA diluted 1:6 in a $10 \mu \mathrm{L}$ reaction volume, including the UniSp6 RNA spike-in using the miRCURY LNA RT kit (QIAGEN, Courtaboeuf, France) according to the manufacturer's protocol.

\section{Real-Time Quantitative qPCR}

Real-Time Quantitative PCR (RT-qPCR) was performed on a 96-well LightCycler 480 instrument (Roche Applied Science, Mannheim, Germany) with $4 \mu \mathrm{L}$ cDNA (diluted 1:40 in sterile water), $1 \mu \mathrm{L}$ PCR primer mix, and $5 \mu \mathrm{L} 2 \mathrm{x}$ miRCURY SYBR Green Master Mix (QIAGEN) in a $10 \mu \mathrm{L}$ reaction volume. First, a quality control for extraction and reverse transcription was performed by measuring endogenous Homo sapiens (hsa)-miR-103a-3p (cutoff of $\leq 32 \mathrm{Cq}$ ) and synthetic UniSp6 RNA (cutoff of $\leq 20 \mathrm{Cq}$ ). Then, we measured hsa-miR-1-3p, hsa-miR-133a-3p, hsa-miR-133b, hsa-miR-206, hsa-miR-208a-3p, hsa-miR208b-3p, hsa-miR$378 \mathrm{a}-3 \mathrm{p}$, and hsa-miR-499a-5p. We chose these miRNAs due to their muscle-specific expression (Lee et $\mathrm{al} .{ }^{24}$ ) and their documented responses to toxic (Siracusa et $a .^{20}$ ) and exercise-related muscle damage (Banzet et al. ${ }^{18}$; Mooren et al..$^{25}$; Baggish et al. ${ }^{19}$ ). PCR protocol consisted in 1 activation cycle $\left(95^{\circ} \mathrm{C}, 2 \mathrm{~min}\right), 52$ amplification cycles (denaturation $95^{\circ} \mathrm{C}, 10 \mathrm{~s}$, and annealing/amplification $56^{\circ} \mathrm{C}, 1 \mathrm{~min}$ ), and a melting curve analysis step, as recommended by the manufacturer. Undetectable values were handled as described by De Ronde et al. ${ }^{26}$ by adding one quantification cycle $(\mathrm{Cq})$ to the highest $\mathrm{Cq}$ observed for a miRNA.

The stability of potent reference miRNAs (hsa-miR-16-5p, hsa-miR-20a-5p, hsa-miR-215p, hsa-miR-103a-3p, hsa-miR-185-5p, hsa-miR-192-5p, hsa-miR-210-3p, and hsa-miR-320a-3p) was assessed using geNorm, BestKeeper, NormFinder, the $\Delta \mathrm{CT}$ method, and RefFinder. The optimal number of reference miRNAs was determined using geNorm. Five reference miRNAs (hsa-miR-16-5p, hsa-miR-20a-5p, hsa-miR-21-5p, hsa-miR-185-5p, and hsa-miR-320a-3p) were deemed sufficient for normalization. Final quantifications are expressed as arbitrary unit (AU) and consisted of the geometrical mean of the quantification performed with each reference miRNA. The raw $\mathrm{Cq}$ and $\mathrm{qPCR}$ primer information are supplied for the target and reference miRNA in Supplementary Table 1. 


\section{Statistics}

Statistical analyses were performed to assess the changes between the PRE, POST, and 24 and $48 \mathrm{~h}$ measurements. Due to the limited sample size of our study and the absence of a normal distribution of the data according to Shapiro-Wilk tests, we performed non-parametric Friedman analysis of variance. Statistical differences between time points were assessed using Dunn's multiple comparisons test. The Friedman test statistic $\chi^{2}$ and the effect size (Kendall's W test value) are reported. The Kendall's W coefficient value range from 0 (no relationship) to 1 (a perfect relationship). Missing data were imputed using the MissMDA R package

Correlations were performed between $\mathrm{CMJ}$ height loss at $24 \mathrm{~h}$ and changes in $\mathrm{CK}, \mathrm{Mb}$, myomiRs and muscle soreness. Indeed, as muscle function (i.e. CMJ height) loss at $24 \mathrm{~h}$ is considered to be the best indirect marker for evaluating the magnitude of exercise-induced muscle damage $^{11}$, any significant correlation suggests that the associated measure could be useful to approach the magnitude of muscle damage. The level of association between parameters was assessed using Spearman's rank correlation coefficient $(\rho)$.

Significance was defined as $p<0.05$. Analyses were performed using GraphPad Prism (Version 8.4.3, GraphPad Software, CA, USA) and R (version 3.6.1, R Core Team (2017). R: A Language and Environment for Statistical Computing, available at: https://www.R-project.org/). All data are presented as the means \pm standard deviation (SD) throughout the manuscript.

\section{Results}

\section{Functional measurements}

\section{Vertical jump}

The Friedman test showed a significant effect of time on CMJ height $\left(P<0.001, \chi^{2}=\right.$ 28.64, Kendall's $\mathrm{W}=0.87$ ). The initial jump height was $19.6 \pm 3.7 \mathrm{~cm}$ (Table 2). CMJ height was reduced by $\sim 84 \%(2.8 \pm 4.1 \mathrm{~cm}, \mathrm{p}<0.001)$ immediately after the race with five of the participants unable to jump (Figure 2). CMJ height remained low, by $\sim 44 \%(10.9 \pm 5.0 \mathrm{~cm}, \mathrm{p}=0.002$; Figure 2) $24 \mathrm{~h}$ after the end of the race. Despite not being statistically different from the PRE values ( $\mathrm{p}=$ $0.19)$, jump height was still reduced by $\sim 30 \%$ at $48 \mathrm{~h}(13.0 \pm 4.6 \mathrm{~cm}$; Figure 2$)$.

\section{Muscle soreness}


The Friedman test showed a significant effect of time on quadriceps muscle soreness $(p<$ 0.001, $\chi^{2}=19.36$, Kendall's $\left.\mathrm{W}=0.587\right)$. The muscle soreness of the athletes was significantly higher immediately and $24 \mathrm{~h}$ after the end of the race (Figure 2).

\section{Biological measurements}

\section{Biochemical analyses}

The Friedman test showed a significant effect of time on CK $\left(P<0.001, \chi^{2}=31.91\right.$, Kendall's W $=0.97), \mathrm{Mb}\left(P<0.001, \chi^{2}=30.00\right.$, Kendall's $\left.\mathrm{W}=1.0\right)$ (Figure 3A), hs-cTnT $(P<$ 0.001, $\chi^{2}=28.90$, Kendall's W $\left.=0.88\right), \mathrm{Cr}\left(P<0.001, \chi^{2}=23.53\right.$, Kendall's W=0.71), and eGFR $\left(P<0.001, \chi^{2}=24.63\right.$, Kendall's $\left.\mathrm{W}=0.75\right) . \mathrm{CK}$ activity was significantly higher between PRE $(137 \pm 112 \mathrm{U} / \mathrm{L}$; Table 2$)$ and POST $(53,239 \pm 63,608 \mathrm{U} / \mathrm{L}, \mathrm{p}<0.001)$ and $24 \mathrm{~h}(19,432 \pm 20,947$ $\mathrm{U} / \mathrm{L}, \mathrm{p}=0.003)$ but there was no significant difference between the PRE and $48 \mathrm{~h}(9,456 \pm 13,767$ $\mathrm{U} / \mathrm{L}, \mathrm{p}=0.29$ ) values (Figure $3 \mathrm{~A}$ ). Mb concentrations were significantly higher between PRE (34 $\pm 19 \mathrm{ng} / \mathrm{mL}$; Table 2) and POST $(9,748 \pm 7997 \mathrm{ng} / \mathrm{mL}, \mathrm{p}<0.001)$ and $24 \mathrm{~h}(669 \pm 585 \mathrm{ng} / \mathrm{mL}, \mathrm{p}=$ $0.002)$ but were not significantly different between PRE and $48 \mathrm{~h}(242 \pm 255 \mathrm{ng} / \mathrm{mL}, \mathrm{p}=0.42)$ values (Figure 3B). The hs-cTnT values were significantly higher in POST $(34.1 \pm 18.3 \mathrm{ng} / \mathrm{L})$ compare to PRE $(6.3 \pm 2.3 \mathrm{ng} / \mathrm{L}, \mathrm{p}<0.001$; Table 2$)$ but there was no significant difference between the PRE and $24 \mathrm{~h}(14.6 \pm 8.0 \mathrm{ng} / \mathrm{L}, \mathrm{p}=0.06)$ or $48 \mathrm{~h}(8.3 \pm 6.9 \mathrm{ng} / \mathrm{L}, \mathrm{p}=1.00)$ values (Figure 3C). There were no significant differences in Cr levels between PRE $(75.6 \pm 14.3 \mu \mathrm{mol} / \mathrm{L}$; Table 2) and POST $(89.7 \pm 15.0 \mu \mathrm{mol} / \mathrm{L}, \mathrm{p}=0.12), 24 \mathrm{~h}(75.0 \pm 18.1 \mu \mathrm{mol} / \mathrm{L}, \mathrm{p}=1.00)$, or $48 \mathrm{~h}$ $(67.2 \pm 13.8 \mu \mathrm{mol} / \mathrm{L}, \mathrm{p}=0.10)$, but the values were significantly lower at $24 \mathrm{~h}$ and $48 \mathrm{~h}$ than at POST (24 h: $\mathrm{p}=0.008,48 \mathrm{~h}: \mathrm{p}<0.001$ ). Similarly, there were no significant differences in the eGFR between PRE $\left(93.8 \pm 9.9 \mathrm{ml} / \mathrm{min} / 1.73 \mathrm{~m}^{2}\right)$ and POST $\left(78.0 \pm 12.8 \mathrm{ml} / \mathrm{min} / 1.73 \mathrm{~m}^{2}, \mathrm{p}=\right.$ $0.12), 24 \mathrm{~h}\left(94.9 \pm 13.0 \mathrm{ml} / \mathrm{min} / 1.73 \mathrm{~m}^{2}, \mathrm{p}=1.00\right)$, or $48 \mathrm{~h}\left(102.6 \pm 8.9 \mathrm{ml} / \mathrm{min} / 1.73 \mathrm{~m}^{2}, \mathrm{p}=0.06\right)$, but the values were significantly lower at 24 and $48 \mathrm{~h}$ than at POST $(24 \mathrm{~h}: \mathrm{p}=0.01,48 \mathrm{~h}: \mathrm{p}<$ $0.001)$.

\section{Circulating miRNA levels}

The Friedman test showed a significant effect of time on the levels of hsa-miR-1-3p $(\mathrm{P}<$ 0.001, $\chi^{2}=23.18$, Kendall's $\left.\mathrm{W}=0.70\right)$, hsa-miR-133a-3p $\left(\mathrm{P}<0.001, \chi^{2}=24.49\right.$, Kendall's $\mathrm{W}=$ 0.74), hsa-miR-133b ( $\mathrm{P}<0.001, \chi^{2}=24.05$, Kendall's $\left.\mathrm{W}=0.73\right)$, hsa-miR-206 $\left(\mathrm{P}<0.001, \chi^{2}=\right.$ 22.75, Kendall's $\mathrm{W}=0.69)$, hsa-miR-208a-3p $\left(\mathrm{P}<0.001, \chi^{2}=20.78\right.$, Kendall's $\left.\mathrm{W}=0.63\right)$, hsa- 
miR-208b-3p $\left(\mathrm{P}<0.001, \chi^{2}=26.02\right.$, Kendall's $\left.\mathrm{W}=0.79\right)$, hsa-miR-378-3p $\left(\mathrm{P}<0.001, \chi^{2}=21.87\right.$, Kendall's $\mathrm{W}=0.66)$, and hsa-miR-499a-5p $\left(\mathrm{P}<0.001, \chi^{2}=28.96\right.$, Kendall's $\left.\mathrm{W}=0.88\right)$. We observed a significant increase in circulating miRNA levels (hsa-miR-1-3p, hsa-miR-133a-3p, hsa-miR-133b, hsa-miR-206, hsa-miR-208a-3p, hsa-miR-208b-3p, hsa-miR-378-3p, and hsa-miR499a-5p) immediately after the 24-h run (fold changes to PRE: 18 to 124,723, p < 0.001). Circulating levels of hsa-miR-499a-5p remained elevated $(p=0.02)$ and hsa-miR-208b-3p tended to remain elevated $(p=0.08) 24 \mathrm{~h}$ after the end of the run (Figure 4$)$.

\section{Correlations with reduced jump height}

Circulating levels of hsa-miR-208a-3p and 208b-3p at the end of the 24-h ultramarathon significantly correlated with the reduction in CMJ height at $24 \mathrm{~h}(\mathrm{p}<0.05)$ and approached significance for hsa-miR-1-3p, hsa-miR-133a-3p, hsa-miR-133b, and hsa-miR-499a-5p ( $<0.07)$ (Figure 5). However, none of these myomiRs were correlated with CMJ height measured immediately after the race. We found no significant correlation between the reduction in CMJ height at $24 \mathrm{~h}$ and $\mathrm{CK}(\mathrm{p}=0.23)$ or $\mathrm{Mb}(\mathrm{p}=0.31)$ levels measured at the end of the 24-h ultramarathon (Figure 5). Finally, no significant correlations were found between $\mathrm{CK}, \mathrm{Mb}, \mathrm{cTnT}$, muscle soreness and myomiRs at each time points.

\section{Discussion}

The main purpose of this study was to investigate the relevance of circulating miRNA levels as biomarkers of muscle damage. We observed an increase in the level of all our target muscle-specific miRNAs immediately after the end of the exercise, which often correlated with muscle function measured $24 \mathrm{~h}$ after the end of the ultramarathon race. By contrast, $\mathrm{CK}$ and $\mathrm{Mb}$ levels did not correlate with muscle function, confirming the hypothesis that myomiR levels may be more representative of muscle damage than most commonly used biomarkers. Our second objective was to examine the acute response of skeletal/cardiac muscle and kidney biomarkers to the 24-h run World Championships in elite athletes. The results confirm the hypothesis that all participants would be diagnosed with exertional rhabdomyolysis immediately after the race, based on increases in $\mathrm{CK}$ and $\mathrm{Mb}$ levels ${ }^{14}$. Hs-cTnT values measured immediately after the race were higher than the $99^{\text {th }}$ percentile upper reference limit (URL), suggesting a high level of cardiac stress. The normal $\mathrm{Cr}$ and eGFR values reported after the race suggest that no significant deterioration of kidney function was induced by the 24-h ultramarathon run. Moreover, despite the 
high level of sarcoplasmic proteins into the bloodstream, kidney function did not seem to be significantly affected.

\section{Acute effect of an ultramarathon on muscle and kidney}

In our study, muscle function measured $24 \mathrm{~h}$ after the end of the exercise was reduced by $\sim 40 \%$ and was still diminished by $\sim 30 \% 48 \mathrm{~h}$ post-exercise. Only one study has previously described the recovery of lower-limb muscle function in the days following an ultramarathon run $^{12}$. The authors ${ }^{12}$ assessed muscle function differently from our study and reported a smaller decrease in muscle function (a loss of $\sim 10-15 \%$ of knee extension and plantar flexion torque at $48 \mathrm{~h}$ post-exercise). This smaller reduction in muscle function is consistent with the smaller CK activity ( 16,000 U/L vs. $\sim 43,000 \mathrm{U} / \mathrm{L})$ and Mb concentration $(\sim 1,400 \mathrm{ng} / \mathrm{mL}$ vs. $\sim 9,700 \mathrm{ng} / \mathrm{mL})$ measured immediately after the $166-\mathrm{km}$ mountain ultramarathon ${ }^{12}$ relative to the results reported here, which suggests a higher degree of muscle damage in our study.

Indeed, all our participants were diagnosed with exertional rhabdomyolysis (CK $>10,000$ U/L) immediately after the race and 8 of 11 still had CK levels above 10,000 U/L 24 h later. A 24$\mathrm{h}$ ultramarathon run is known to induce exertional rhabdomyolysis. However, the $\mathrm{CK}$ and $\mathrm{Mb}$ responses were higher in our study than those of Martin et al. ${ }^{3}$ and Waśkiewicz et al. ${ }^{4}$. The higher distance covered by our athletes relative to those of the above-mentioned studies ${ }^{3,4}$ ( $\sim 230 \mathrm{~km}$ vs. 150-170 km) may explain the higher CK activity. Indeed, the duration of exercise may increase the degree of muscle damage ${ }^{27}$. Accordingly, the CK activity observed after the race in our study is consistent with the values reported after the $246-\mathrm{km}$ Spartathlon running race ${ }^{28}$. On the other hand, despite the higher level of muscle damage markers observed after the 24-h ultramarathon relative to those reported by Millet et al. ${ }^{12}$, our participants reported a similar level of muscle soreness, suggesting that elite athletes are less susceptible to muscle soreness.

Despite the large increase of intramuscular protein content in the blood, in particular $\mathrm{Mb}$, only 1 of 11 participants showed a significant change in acute kidney injury biomarker levels immediately after the race (absolute increase in Cr: $29 \mu \mathrm{mol}$, eGFR: $60 \mathrm{~mL} / \mathrm{min} / 1.73 \mathrm{~m}^{2}$ ). These biomarker values were not beyond the pathological limit (defined by an absolute increase in $\mathrm{Cr}>$ $26.5 \mu \mathrm{mol}$ and eGFR $\left.<60 \mathrm{~mL} / \mathrm{min} / 1.73 \mathrm{~m}^{2}\right)^{9}$ for the 10 other athletes and returned to normal $24 \mathrm{~h}$ after the ultramarathon for all runners. The transient and low-to-moderate alterations of kidney function we observed in the elite athletes are different than those observed by Hoffman $\&$ Weiss ${ }^{29}$. Indeed, they reported that more than $40 \%$ of the 585 runners were diagnosed with acute kidney 
injury, whereas none of our participants met the criterion (1.5X baseline Cr values). Although our study was not designed to assess this question, external (e.g. race characteristics, environmental conditions) or internal factors (e.g. training level, genetic profiles, sex) may at least partially explain these discrepancies? ${ }^{7}$.

All our participants presented a hs-cTnT value higher than the $99^{\text {th }}$ percentile URL (10 $\mathrm{ng} / \mathrm{g}$ for women and $15 \mathrm{ng} / \mathrm{L}$ for $\mathrm{men}^{30}$ ) at this time point, whereas none of them showed any such values before the race. Our results thus suggest a high level of cardiac stress immediately after the 24-h ultramarathon race. This finding is consistent with the increase in cardiac specific troponin $\mathrm{T}$ levels observed immediately after another 24-h ultramarathon run $^{5}$. Although the troponin assay was of a different generation in this study, the values for well-trained athletes $\left(\sim 0.01 \mathrm{ng} / \mathrm{mL}^{5}\right)$ were comparable to our values $(34 \mathrm{ng} / \mathrm{L})$. Indeed, Sandoval et al. ${ }^{30}$ reported that a hs-cTnT value of $30 \mathrm{ng} / \mathrm{L}$ is similar to a fourth-generation troponin $\mathrm{T}$ value of $0.01 \mathrm{ng} / \mathrm{mL}$. However, the values we measured immediately after the race were lower than those reported after a marathon run ( $\sim 00$ ng/L vs. $\left.34 \mathrm{ng} / \mathrm{L}^{31}\right)$. This is probably due to the lower exercise intensity during an ultra-long distance run than during a marathon ${ }^{32}$. In our study, the hs-cTnT values measured 24 and $48 \mathrm{~h}$ after the end of the race decreased relatively rapidly (Figure 3C). Only 6 of the 11 participants still had values above the $99^{\text {th }}$ percentile URL at $24 \mathrm{~h}$ and only three of them at $48 \mathrm{~h}$. Consequently, the relatively small increase in hs-cTnT levels relative to the MI cut-off threshold ( $\left.>100 \mathrm{ng} / \mathrm{L}^{30}\right)$, the rapid recovery kinetics (Figure 3C), and the absence of symptoms in our study suggest the nonpathological release of cTnT that is likely explained by the release of unbound cytosolic cTnT rather than cardiomyocyte necrosis ${ }^{32}$.

\section{Change in circulating miRNA levels}

The levels of all our target plasma miRNAs significantly increased immediately after the race relative to baseline values, suggesting that myomiR levels are sensitive to ultra-endurance exercise. This response to exercise has been already observed under various conditions of exercise ${ }^{18,25,33-35}$. Although no study has investigated circulating myomiR levels after ultraendurance races (known to be a good model of muscle damage ${ }^{3,12}$ ), several have shown an increase after marathon runs ${ }^{25,34,35}$. Similar to our results, these studies described an increase in circulating miR-1, miR-133a, miR-206, miR-208b, and miR-499a immediately after the exercise. However, the magnitude of the increase was smaller than that reported here, maybe due to shorter exercise duration and therefore less exercise-induced muscle damage and/or a shorter duration of 
release. Indeed, these studies ${ }^{25,34,35}$ reported lower CK responses ( $\sim 600 \mathrm{U} / \mathrm{L}, \sim 4 \mathrm{X}$ baseline value, $\sim 2,000 \mathrm{U} / \mathrm{L})$ than observed in our study. Circulating miRNA has often been reported to have a short half-life in the blood and a large body of evidence suggests rapid clearance from the circulation following acute tissue injury (skeletal and cardiac muscles and liver), possibly through renal elimination ${ }^{36}$ or tissue uptake/biodistribution ${ }^{37}$. However, the clearance mechanisms of circulating miRNA are poorly understood and it cannot be excluded that the rate of miRNA liberation into the blood exceeds the rate of clearance in the context of EIMD extended over $24 \mathrm{~h}$. On the other hand, not all previous studies that investigated miRNA responses after exercise interpreted elevated levels of circulating miRNA as being indicative of muscle damage. For example, Mooren et al ${ }^{25}$ suggested that myomiRs could be biomarkers of aerobic exercise capacity. Ramos et al. ${ }^{33}$ showed that circulating miR-1 and miR-133a levels were related to the intensity and duration of endurance running, suggesting that miRNAs could mediate physiological adaptation to exercise. Indeed, Guescini et al. ${ }^{38}$ showed that extracellular vesicles originating from the skeletal muscle may be enriched in myomiRs, which are known to be involved in muscle homeostasis ${ }^{39}$.

Whether the circulating miRNAs quantified in our study are released in the blood due to active secretion or passively leaked from injured myocytes due to EIMD cannot be determined with the current experimental setting. However, post-exercise fold changes reported in previous studies $^{19,25,33}$ were considerably lower than those reported here (fold changes: 18-124,723). Ramos et al. ${ }^{33}$ found that miR-1 and miR-133a fold changes were up to 5 after 90 min running and other authors (Baggish et al. ${ }^{19}$; De Gonzalo-Calvo et al. ${ }^{40}$ ) found that miR-1, miR-133a, mir-133b and miR-499 fold changes were up to 18.5 after a marathon run. Thus, the large increases in circulating miRNA levels that we observed were unlikely solely due to exercise-induced secretion ${ }^{33}$ but also to leakage from injured myocytes ${ }^{18}$. Indeed, the increase in circulating miRNA levels observed after the 24-h ultramarathon in our study is higher than that reported after toxic muscle injury in rats ${ }^{20}$. High circulating miRNA levels have also been reported in human studies on pathological ${ }^{21,22}$ and physiological ${ }^{18}$ muscle damage. Banzet et al. ${ }^{18}$ reported an elevation in the level of several circulating myomiRs in the plasma after an eccentric exercise known to induce EIMD but not after a concentric exercise. A positive correlation was found between miR-133a and CK levels ${ }^{25}$ and between miR-1/miR-133a and CK/troponin T levels ${ }^{35}$, suggesting that these myomiRs may be useful for the diagnosis of muscle damage and cardiac stress. Although we did not find a correlation between myomiR and CK/troponin $\mathrm{T}$ levels in our study, the positive 
correlations observed between the level of some myomiRs and muscle function loss $24 \mathrm{~h}$ after the race suggest that circulating myomiRs were representative of the level of muscle damage. However, whether the release was actively secreted by or passively leaked out of injured myocytes remains to be documented.

\section{Interest of biomarkers of delayed muscle function loss}

In the present study, the $\mathrm{CK}$ activity and $\mathrm{Mb}$ concentration measured immediately after the end of exercise did not correlate with the muscle function measured $24 \mathrm{~h}$ later, suggesting that these biomarkers do not reflect the magnitude of exercise-induced muscle damage. These results are consistent with those of Damas et al. ${ }^{16}$, who observed high interindividual variability of CK activity relative to the degree of muscle function loss after eccentric elbow flexor contractions. Our results are also consistent with the lack of an accepted cut-off threshold for CK activity (e.g. 5-10X the upper limit range or $>5,000-10,000 \mathrm{U} / \mathrm{L})^{14}$ and $\mathrm{Mb}$ concentration (400 to 4,000 $\mathrm{ng} / \mathrm{mL})^{15}$ to determine a pathological state. Thus, although these commonly used biomarkers of exertional rhabdomyolysis are still of great utility to detect the presence of muscle damage their ability to quantify the magnitude of muscle damage appears to be limited.

We found significant or nearly significant correlations between the level of most of our target circulating miRNAs measured immediately after the 24-h ultramarathon and muscle function measured $24 \mathrm{~h}$ later. However, we found no correlations between loss of muscle function at $24 \mathrm{~h}$ and $\mathrm{CK}$ activities or Mb levels, suggesting that myomiRs may be more relevant than $\mathrm{CK}$ or $\mathrm{Mb}$ to represent the magnitude of muscle damage in our study (Figure 5). Although more studies are required to confirm this assumption, these results are consistent with those of Siracusa et al. ${ }^{20}$, who reported that the accuracy in discriminating damaged from nondamaged muscle in rats was lower for CK than myomiRs. Moreover, our results are also concordant with those of another study ${ }^{18}$, which reported that circulating myomiR levels are able to discriminate between uphill and downhill walking exercises, whereas $\mathrm{CK}$ activity and Mb concentration were not, suggesting that myomiRs may be more sensitive and specific to muscle damage.

In addition, hsa-miR-206, hsa-miR-208b-3p and hsa-miR-499a-5p may be of additional interest due to their low circulating levels, as they are often undetectable in the absence of muscle damage (Figure 4) ${ }^{18,20}$. Indeed, it has been shown that hsa-miR-206 was undetectable after lowlevel muscle damage (loss of $\sim 15 \%$ of muscle function at $24 \mathrm{~h}^{18}$ ), whereas a high level was detected after a marathon run ${ }^{25}$ and in the present study. Moreover, hsa-miR-208b-3p and hsa- 
miR-499a-5p appear to have additional utility relative to other myomiRs because their plasma levels were still elevated $24 \mathrm{~h}$ after the end of the 24-h ultramarathon (Figure 4). We found no significant correlation between the circulating levels of these miRNAs measured $24 \mathrm{~h}$ after the end of the ultramarathon and muscle function, suggesting limited utility for monitoring recovery after muscle injury (24 - 48 h). Previous work has shown that some myomiRs could remain elevated up to $24 \mathrm{~h}$ after tissue injury. For instance, miR-1 was still elevated at $24 \mathrm{~h}$ in the serum of rats after an acute myocardial infarctus (Cheng et al. ${ }^{41}$ ). Similar patterns were also reported in the plasma of rats following an acute myotoxic injury, where miR-208b remained elevated at $24 \mathrm{~h}$ but not the others myomiRs (Siracusa et $\mathrm{al}^{20}$ ). However, there are no strong arguments to explain these kinetics. MyomiRs appear to exert various role in muscle biology. For instance, miR-1 and miR206 target Pax3 during the process of myogenesis (Goljanek-Whysall et al. ${ }^{42}$ ), while miR-208b and miR-499 have a redundant role in maintaining slow myofiber and repressing fast myofiber phenotype (Van Rooij et al. ${ }^{43}$ ). Given that the circulating levels of all our myomiRs correlated well with each other, it may not be necessary to simultaneously measure them all in clinical practice. As suggested by Siracusa et al. ${ }^{20}$, assessment of cardiac- and skeletal muscle-specific miRNA (i.e. hsa-miR-208a, hsa-miR-208b, and hsa-miR-133b or miR-206) could provide sufficient information to diagnose muscle damage.

Surprisingly, hsa-miR-208a-3p strongly correlated with muscle function in the present study, although this myomiR is cardiac-specific ${ }^{22}$ and is not detected after toxic muscle injury in rats $^{20}$ and downhill walking in humans ${ }^{18}$. It is possible that subjects exhibiting high levels of cardiac stress were also those who underwent a high degree of muscle damage. Covariates, such as exercise intensity or training experience, may affect both muscle damage ${ }^{44}$ and cardiac stress ${ }^{32}$ and may therefore explain this surprising correlation. We found no significant correlation between hscTnT levels measured immediately after the race and CMJ measured $24 \mathrm{~h}$ later, which does not support this hypothesis. However, no correlation has been found between miR-208a, troponin, and cardiac function parameters in acute myocardial infarction and coronary heart disease ${ }^{45}$. Consequently, more studies are required to interpret the magnitude in the change of the levels of cardiac-damage biomarkers.

\section{Limitations of the study}

Our study had several limitations. First, we included a relatively small number of participants due to the limited number of athletes on the French national team, which did not allow 
to test a potential effect of sex. However, Duttagupta et al. ${ }^{46}$ showed that myomiRs were not mentioned among miRNAs differently expressed between male and female. Nielsen et al. ${ }^{47}$ found an effect of sex in myomiRs expression (mice; 133a and 133b) in resting skeletal muscle in relation to testosterone, however they also found that aerobic exercise training seems to override any effects of testosterone. Therefore, it seems that the potential difference in myomiR expression in skeletal muscle does not seem to translate into a different circulating myomiR level. Moreover, Siracusa et al. ${ }^{20}$ found similar circulating myomiR levels between female and male rats at baseline and in response to muscle damage. Taken together, these results suggest that circulating myomiRs were likely not substantially affected by sex in our study. Second, the experimental group of this study was restricted to elite athletes in a world championship context. On one hand, more studies are required to determine whether the present miRNA results may be replicated and apply to a wider population. On the other hand, this kind of competitive event may lead to an important physiological stress. Therefore, it could induce health problems requiring rigorous medical monitoring 7 . In this context, the assessment of scientific measures could be secondary and therefore reduce the access to the athletes. Third, as dietary intakes were not controlled during the present race because it is impossible in the context of ultra-endurance competitions (Lavoue et al. ${ }^{2}$ ), interindividual differences could have affected circulating miRNA levels (Mantilla-Escalente et $\mathrm{al}^{48}$ ). Fourth, despite the use of a reliable and reproducible RT-qPCR normalization technique ${ }^{49}$, it is impossible to compare results from different studies without considering control values (i.e. healthy resting subject values). Therefore, no clinical recommendation can be provided with this type of normalization. Finally, as plasma miRNA levels assessment is a long process ( 6 $\mathrm{h}$; including RNA extraction and RT-qPCR), this biomarker is not compatible with medical emergency (e.g. exertional rhabdomyolysis, acute kidney injury). Therefore, further research is needed to the development of faster analytic methods that may be appropriate for point-of-care tests. Recently developed novel PCR-free techniques ${ }^{50}$ may allow more widespread use of circulating miRNA as biomarkers of muscle damage in the future.

\section{Perspectives}

All elite ultramarathon runners included in our study were diagnosed with exertional rhabdomyolysis $(\mathrm{CK}>10,000 \mathrm{U} / \mathrm{L})$ after the 24-h run World Championships. However, despite the high level of sarcoplasmic proteins into the bloodstream, the deterioration of kidney function 
was relatively moderate and transient in this population. Further research is needed to investigate factors explaining the potential lower susceptibility of world-class/elite athletes to acute kidney injury. The elevation of cardiac biomarkers was likely due to exercise-related cytosolic release rather than cardiac necrosis. Importantly, the present study is the first to show that muscle-specific miRNAs were more associated with the magnitude of muscle function loss than $\mathrm{CK}$ and $\mathrm{Mb}$, suggesting that myomiRs may be useful to approach the magnitude of muscle damage. Specifically, assessment of both cardiac- and skeletal muscle-specific miRNA such as hsa-miR208a, hsa-miR-208b and hsa-miR-133b or hsa-miR-206 could be a good approach to diagnose muscle damage.

MyomiRs may have a future interest in the diagnosis of muscle damage both in sport medicine and in the monitoring of physical activity. However, further research is needed for a better understanding of the release mechanisms and intercellular communication roles of these circulating miRNAs.

\section{Acknowledgments}

The authors thank the athletes and technical staff of Emmanuel FONTAINE, Patrice BINELLI, Frédéric BARREDA, and Cindie DECHAMBRE for their time. We also thank Laura BILLON, Carole BOIVERT, Pascal CHOURROUT, and the IRBA Molecular Biology Unit for their technical support. Finally, we thank Keyne CHARLOT (Laboratoire Graphique) for designing the figures.

\section{Conflict of interest}

The authors declare no conflicts of interest, financial or otherwise. Furthermore, the authors declare that the results of the study are presented clearly, honestly, and without fabrication, falsification, or inappropriate data manipulation.

\section{Data Availability Statement:}

The data that support the findings of this study are available from the corresponding author upon reasonable request.

\section{REFERENCES}


1. Bossi AH, Matta GG, Millet GY, et al. Pacing Strategy During 24-Hour Ultramarathon-Distance Running. International journal of sports physiology and performance. 2017;12(5):590-596.

2. Lavoué C, Siracusa J, Chalchat É, Bourrilhon C, Charlot K. Analysis of food and fluid intake in elite ultra-endurance runners during a 24-h world championship. Journal of the International Society of Sports Nutrition. 2020;17(1):36.

3. Martin V, Kerherve $H$, Messonnier LA, et al. Central and peripheral contributions to neuromuscular fatigue induced by a 24-h treadmill run. Journal of applied physiology (Bethesda, Md : 1985). 2010;108(5):1224-1233.

4. Waśkiewicz Z, Kłapcińska B, Sadowska-Krępa E, et al. Acute metabolic responses to a 24-h ultramarathon race in male amateur runners. European journal of applied physiology. 2012;112(5):1679-1688.

5. Hohl R, Nazario de Rezende F, Millet GY, Ribeiro da Mota G, Marocolo M. Blood cardiac biomarkers responses are associated with $24 \mathrm{~h}$ ultramarathon performance. Heliyon. 2019;5(6):e01913.

6. Donnellan E, Phelan D. Biomarkers of Cardiac Stress and Injury in Athletes: What Do They Mean? Current Heart Failure Reports. 2018;15(2):116-122.

7. Rojas-Valverde D, Sanchez-Urena B, Crowe J, Timon R, Olcina GJ. Exertional rhabdomyolysis and acute kidney injury in endurance sports: A systematic review. European journal of sport science. 2020:1-14.

8. Petejova N, Martinek A. Acute kidney injury due to rhabdomyolysis and renal replacement therapy: a critical review. Critical care. 2014;18(3):224.

9. Makris K, Spanou L. Acute Kidney Injury: Definition, Pathophysiology and Clinical Phenotypes. The Clinical biochemist Reviews. 2016;37(2):85-98.

10. Maeo $S$, Yamamoto $M$, Kanehisa H. Downhill walking training with and without exercise-induced muscle damage similarly increase knee extensor strength. Journal of sports sciences. 2016;34(21):2018-2026.

11. Warren GL, Lowe DA, Armstrong RB. Measurement tools used in the study of eccentric contraction-induced injury. Sports medicine. 1999;27(1):43-59.

12. Millet GY, Tomazin $\mathrm{K}$, Verges $\mathrm{S}$, et al. Neuromuscular consequences of an extreme mountain ultramarathon. PloS one. 2011;6(2):e17059.

13. Lippi G, Schena F, Ceriotti F. Diagnostic biomarkers of muscle injury and exertional rhabdomyolysis. Clinical chemistry and laboratory medicine. 2018;57(2):175-182.

This article is protected by copyright. All rights reserved 
14. Stahl K, Rastelli E, Schoser B. A systematic review on the definition of rhabdomyolysis. Journal of Neurology. 2020;267(4):877-882.

15. Servonnet A, Dubost C, Martin G, et al. Myoglobin: still a useful biomarker in 2017? Annales de biologie clinique. 2018;76(2):137-141.

16. Damas F, Nosaka K, Libardi CA, Chen TC, Ugrinowitsch C. Susceptibility to Exercise-Induced Muscle Damage: a Cluster Analysis with a Large Sample. International journal of sports medicine. 2016;37(8):633-640.

17. Paulsen G, Mikkelsen UR, Raastad T, Peake JM. Leucocytes, cytokines and satellite cells: what role do they play in muscle damage and regeneration following eccentric exercise? Exercise immunology review. 2012;18:42-97.

18. Banzet $S$, Chennaoui $M$, Girard $O$, et al. Changes in circulating microRNAs levels with exercise modality. Journal of applied physiology (Bethesda, Md : 1985). 2013;115(9):1237-1244.

19. Baggish AL, Park J, Min PK, et al. Rapid upregulation and clearance of distinct circulating microRNAs after prolonged aerobic exercise. Journal of applied physiology (Bethesda, Md : 1985). 2014;116(5):522-531.

20. Siracusa J, Koulmann N, Bourdon S, Goriot ME, Banzet S. Circulating miRNAs as Biomarkers of Acute Muscle Damage in Rats. The American journal of pathology. 2016;186(5):1313-1327.

21. Cacchiarelli D, Legnini I, Martone J, et al. miRNAs as serum biomarkers for Duchenne muscular dystrophy. EMBO molecular medicine. 2011;3(5):258-265.

22. D'Alessandra $Y$, Devanna $P$, Limana $F$, et al. Circulating microRNAs are new and sensitive biomarkers of myocardial infarction. European Heart Journal. 2010;31(22):2765-2773.

23. Corsten MF, Dennert R, Jochems S, et al. Circulating MicroRNA-208b and MicroRNA-499 reflect myocardial damage in cardiovascular disease. Circulation: Cardiovascular Genetics'. 2010;3(6):499-506.

24. Lee EJ, Baek M, Gusev Y, Brackett DJ, Nuovo GJ, Schmittgen TD. Systematic evaluation of microRNA processing patterns in tissues, cell lines, and tumors. Rna. 2008;14(1):35-42.

25. Mooren FC, Viereck J, Kruger K, Thum T. Circulating microRNAs as potential biomarkers of aerobic exercise capacity. American journal of physiology Heart and circulatory physiology. 2014;306(4):H557-563.

26. De Ronde MWJ, Ruijter JM, Lanfear D, et al. Practical data handling pipeline improves performance of qPCR-based circulating miRNA measurements. Rna. 2017;23(5):811-821.

27. Clarkson PM, Hubal MJ. Exercise-induced muscle damage in humans. American journal of physical medicine \& rehabilitation. 2002;81(11 Suppl):S52-69.

This article is protected by copyright. All rights reserved 
28. Skenderi KP, Kavouras SA, Anastasiou CA, Yiannakouris N, Matalas AL. Exertional Rhabdomyolysis during a 246-km continuous running race. Medicine and science in sports and exercise. 2006;38(6):1054-1057.

29. Hoffman MD, Weiss RH. Does Acute Kidney Injury From an Ultramarathon Increase the Risk for Greater Subsequent Injury? Clinical journal of sport medicine : official journal of the Canadian Academy of Sport Medicine. 2016;26(5):417-422.

30. Sandoval Y, Jaffe AS. Using High-Sensitivity Cardiac Troponin T for Acute Cardiac Care. The American journal of medicine. 2017;130(12):1358-1365.e1351.

31. Baker $P$, Leckie $T$, Harrington D, Richardson A. Exercise-induced cardiac troponin elevation: An update on the evidence, mechanism and implications. International journal of cardiology. 2019;22:181-186.

32. Gresslien T, Agewall S. Troponin and exercise. International Journal Cardiology. 2016;221:609621.

33. Ramos $A E$, Lo $C$, Estephan $L E$, et al. Specific circulating microRNAs display dose-dependent responses to variable intensity and duration of endurance exercise. American journal of physiology Heart and circulatory physiology. 2018;315(2):H273-H283.

34. Baggish AL, Hale A, Weiner RB, et al. Dynamic regulation of circulating microRNA during acute exhaustive exercise and sustained aerobic exercise training. The Journal of physiology. 2011;589(Pt 16):3983-3994.

35. Clauss S, Wakili R, Hildebrand B, et al. MicroRNAs as Biomarkers for Acute Atrial Remodeling in Marathon Runners (The miRathon Study--A Sub-Study of the Munich Marathon Study). PloS one. 2016;11(2):e0148599-e0148599.

36. Cheng $\mathrm{Y}$, Wang $\mathrm{X}$, Yang J, et al. A translational study of urine miRNAs in acute myocardial infarction. Journal of Molecular and Cellular Cardiology. 2012;53(5):668-676.

37. Bala S, Csak T, Momen-Heravi F, et al. Biodistribution and function of extracellular miRNA-155 in mice. Scientific reports. 2015;5:10721.

38. Guescini M, Canonico B, Lucertini F, et al. Muscle Releases Alpha-Sarcoglycan Positive Extracellular Vesicles Carrying miRNAs in the Bloodstream. PloS one. 2015;10(5):e0125094.

39. Diniz GP, Wang DZ. Regulation of Skeletal Muscle by microRNAs. Comprehensive Physiology. 2016;6(3):1279-1294.

40. de Gonzalo-Calvo D, Dávalos A, Montero A, et al. Circulating inflammatory miRNA signature in response to different doses of aerobic exercise. Journal of applied physiology (Bethesda, Md: 1985). 2015;119(2):124-134.

This article is protected by copyright. All rights reserved 
41. Cheng $\mathrm{Y}$, Tan N, Yang J, et al. A translational study of circulating cell-free microRNA-1 in acute myocardial infarction. Clinical science (London, England : 1979). 2010;119(2):87-95.

42. Goljanek-Whysall K, Sweetman D, Abu-Elmagd M, et al. MicroRNA regulation of the paired-box transcription factor Pax3 confers robustness to developmental timing of myogenesis. Proceedings of the National Academy of Sciences of the United States of America. 2011;108(29):11936-11941.

43. van Rooij E, Quiat D, Johnson BA, et al. A family of microRNAs encoded by myosin genes governs myosin expression and muscle performance. Developmental Cell. 2009;17(5):662-673.

44. Ertel KA, Hallam JE, Hillman AR. The effects of training status and exercise intensity on exerciseinduced muscle damage. The Journal of sports medicine and physical fitness. 2020;60(3):449-455.

45. Nabiałek E, Wańha W, Kula D, et al. Circulating microRNAs (miR-423-5p, miR-208a and miR-1) in acute myocardial infarction and stable coronary heart disease. Minerva Cardioangiolica. 2013;61(6):627-637.

46. Duttagupta R, Jiang R, Gollub J, Getts RC, Jones KW. Impact of cellular miRNAs on circulating miRNA biomarker signatures. PloS one. 2011;6(6):e20769.

47. Nielsen $S$, Hvid $T$, Kelly $M$, et al. Muscle specific miRNAs are induced by testosterone and independently upregulated by age. Frontiers in physiology. 2013;4:394.

48. Mantilla-Escalante DC, López de Las Hazas MC, Gil-Zamorano J, et al. Postprandial Circulating miRNAs in Response to a Dietary Fat Challenge. Nutrients. 2019;11(6).

49. Faraldi M, Gomarasca M, Banfi G, Lombardi G. Free Circulating miRNAs Measurement in Clinical Settings: The Still Unsolved Issue of the Normalization. Advances in Clinical Chemistry. 2018;87:113-139.

50. Anfossi S, Babayan A, Pantel K, Calin GA. Clinical utility of circulating non-coding RNAs - an update. Nature Reviews Clinical Oncology. 2018;15(9):541-563.

\section{SUPPLEMENTAL DIGITAL CONTENT}

Supplementary Table 1.xlsx

\section{FIGURE LEGENDS}

Figure 1. Aerial view of the race loop. The aerial view was extracted from ${ }^{\circledR}$ Google Maps.

Figure 2. Changes in counter movement jump (CMJ) height (A) and muscle soreness of the 
quadriceps (B) after the 24-h ultramarathon run. CMJ height and muscle soreness values are expressed as \%PRE and mm (on $0-100 \mathrm{~mm}$ scale), respectively. Data are displayed as interquartile ranges $\left(25^{\text {th }}\right.$ and $75^{\text {th }}$ percentiles, colored boxes), medians (horizontal white bars), minimummaximum (whiskers), and individual values (dots). *: $\mathrm{p}<0.05, * * \mathrm{p}<0.01, * * * \mathrm{p}<0.001$.

Figure 3. Changes in creatine kinase activity (A), myoglobin concentration (B), and highsensitive cardiac troponin $T$ (hs-cTnT) concentration (C) after the 24-h ultramarathon run. Data are expressed as interquartile ranges $\left(25^{\text {th }}\right.$ and $75^{\text {th }}$ percentiles, colored boxes), medians (horizontal white bars), minimum-maximum (whiskers), and individual values (dots). ${ }^{*} \mathrm{p}<0.05$, $* * \mathrm{p}<0.01, * * * \mathrm{p}<0.001$.

Figure 4. Changes in plasma miRNA levels after the 24-h ultramarathon run for homo sapiens (hsa)-miR-1-3p (A), hsa-miR-133a-3p (B), hsa-miR-133b (C), hsa-miR-206 (D), hsamiR-208a-3p (E), hsa-miR-208b-3p (F), hsa-miR-378a-3p (G), and hsa-miR-499a-5p (H). Data are expressed as the relative abundance arbitrary unit (AU) and are displayed as interquartile ranges $\left(25^{\text {th }}\right.$ and $75^{\text {th }}$ percentiles, colored boxes), medians (horizontal white bars), minimum, maximum (whiskers), and individual values (dots). ${ }^{*} \mathrm{p}<0.05, * * \mathrm{p}<0.01, * * *: \mathrm{p}<0.001$.

Figure 5. Correlation between the magnitude of the reduction of counter movement jump (CMJ) height measured $24 \mathrm{~h}$ after the end of the 24-h ultramarathon run and plasma miRNA levels measured immediately after the end of the race. Data are displayed for homo sapiens (hsa)-miR-1-3p (A), hsa-miR-133a-3p (B), hsa-miR-133b (C), hsa-miR-206 (D), hsa-miR208a-3p (E), hsa-miR-208b-3p (F), hsa-miR-378a-3p (G), and hsa-miR-499a-5p (H). CMJ height loss values are expressed as \%PRE, plasma miRNA levels as relative abundance arbitrary unit $(\mathrm{AU})$, creatine kinase activity as $\mathrm{U} / \mathrm{L}$, and myoglobin concentration as $(\mathrm{ng} / \mathrm{mL})$. 


\section{TABLES}

Table 1- Participant characteristics

\begin{tabular}{|c|c|c|c|c|c|c|c|c|c|c|c|}
\hline & Sex & Age & Height & Weight & BMI & Fat mass & Performance* & Ranking** & Experie & nce in UM & Training \\
\hline \# & $\mathrm{M}$ or $\mathrm{F}$ & years & $\mathrm{cm}$ & $\mathrm{kg}$ & kg.m-2 & $\%$ of weight & $\mathrm{km}(\% v s \mathrm{~PB})$ & & years & $\begin{array}{c}\text { number of } \\
24-h\end{array}$ & h.week ${ }^{-1}$ \\
\hline 1 & $\mathrm{M}$ & 39 & 181 & 75 & 22,9 & 4,2 & $272(+7)$ & 4 & 20 & 1 & 15 \\
\hline 2 & M & 53 & 170 & 60 & 20,8 & 6,2 & $259(-2)$ & 12 & 9 & 20 & 27 \\
\hline 3 & M & 53 & 172 & 63,1 & 21,3 & 8,9 & $248(-1)$ & 19 & 5 & 4 & 6 \\
\hline 4 & M & 46 & 188 & 73,8 & 20,9 & 14,5 & $236(-6)$ & 31 & 9 & 6 & 15 \\
\hline 5 & M & 50 & 175 & 69,5 & 22,7 & 9,7 & $236(-6)$ & 34 & 4 & 8 & 14 \\
\hline 6 & $\mathrm{~F}$ & 37 & 160 & 42,9 & 16,8 & 10,1 & $241(+12)$ & 7 & 4 & 1 & 12 \\
\hline 7 & $\mathrm{~F}$ & 52 & 166 & 53,1 & 19,3 & 23,5 & $222(-7)$ & 21 & 13 & 16 & 6 \\
\hline 8 & $\mathrm{~F}$ & 45 & 160 & 51,9 & 20,3 & 19,1 & $219(+4)$ & 26 & 6 & 3 & 8 \\
\hline 9 & $\mathrm{~F}$ & 46 & 160 & 62,9 & 24,6 & 18,6 & $209(-7)$ & 36 & 13 & 2 & 10 \\
\hline 10 & $\mathrm{~F}$ & 31 & 171 & 58 & 19,8 & 12 & $201(-4)$ & 49 & 8 & 3 & 10 \\
\hline 11 & $\mathrm{~F}$ & 52 & 169 & 61,4 & 21,5 & 22,2 & $193(-9)$ & 58 & 9 & 2 & 8 \\
\hline Mean (M) & & $48.2 \pm 5.9$ & $177 \pm 7$ & $68.3 \pm 6.6$ & $21.7 \pm 1.0$ & $8.7 \pm 3.9$ & $250 \pm 15$ & $20 \pm 13$ & $9.4 \pm 6.3$ & $7.8 \pm 7.3$ & $15 \pm 8$ \\
\hline Mean $(F)$ & & $43.8 \pm 8.4$ & $164 \pm 5$ & $55.0 \pm 7.4$ & $20.4 \pm 2.6$ & $17.6 \pm 5.4$ & $214 \pm 17$ & $33 \pm 19$ & $8.8 \pm 3.6$ & $4.5 \pm 5.7$ & $9 \pm 2$ \\
\hline Mean & & $45.8 \pm 7.4$ & $170 \pm 9$ & $61.1 \pm 9.6$ & $21.0 \pm 2.1$ & $13.5 \pm 6.5$ & $231 \pm 24$ & $27 \pm 17$ & $9.1 \pm 4.8$ & $6.0 \pm 6.4$ & $12 \pm 6$ \\
\hline
\end{tabular}

BMI: body mass index, UM: ultramarathon, PB: personal best previous performance in 24-h races

* Values into brackets represent the difference between the performance in this race and their previous best performance (PB). ** 214 and 147 participants started the race in male and female category, respectively.

Table 2 - Initial absolute values of the different measurements.

$\mathrm{CMJ}(\mathrm{cm})$

Creatine kinase (U.L-1)

Myoglobin (ng.mL ${ }^{-1}$ )

Hs-cTnT (ng.L-1)

Creatinine $\left(\mu \mathrm{mol} . \mathrm{L}^{-1}\right)$
$19.6 \pm 3.7$

$137.3 \pm 112.4$

$34.2 \pm 18.7$

$6.3 \pm 2.3$

$75.6 \pm 14.3$

Means \pm SD. CMJ : Counter-movement jump; Hs-cTnT : high-sensitive cardiac troponin T.

This article is protected by copyright. All rights reserved 


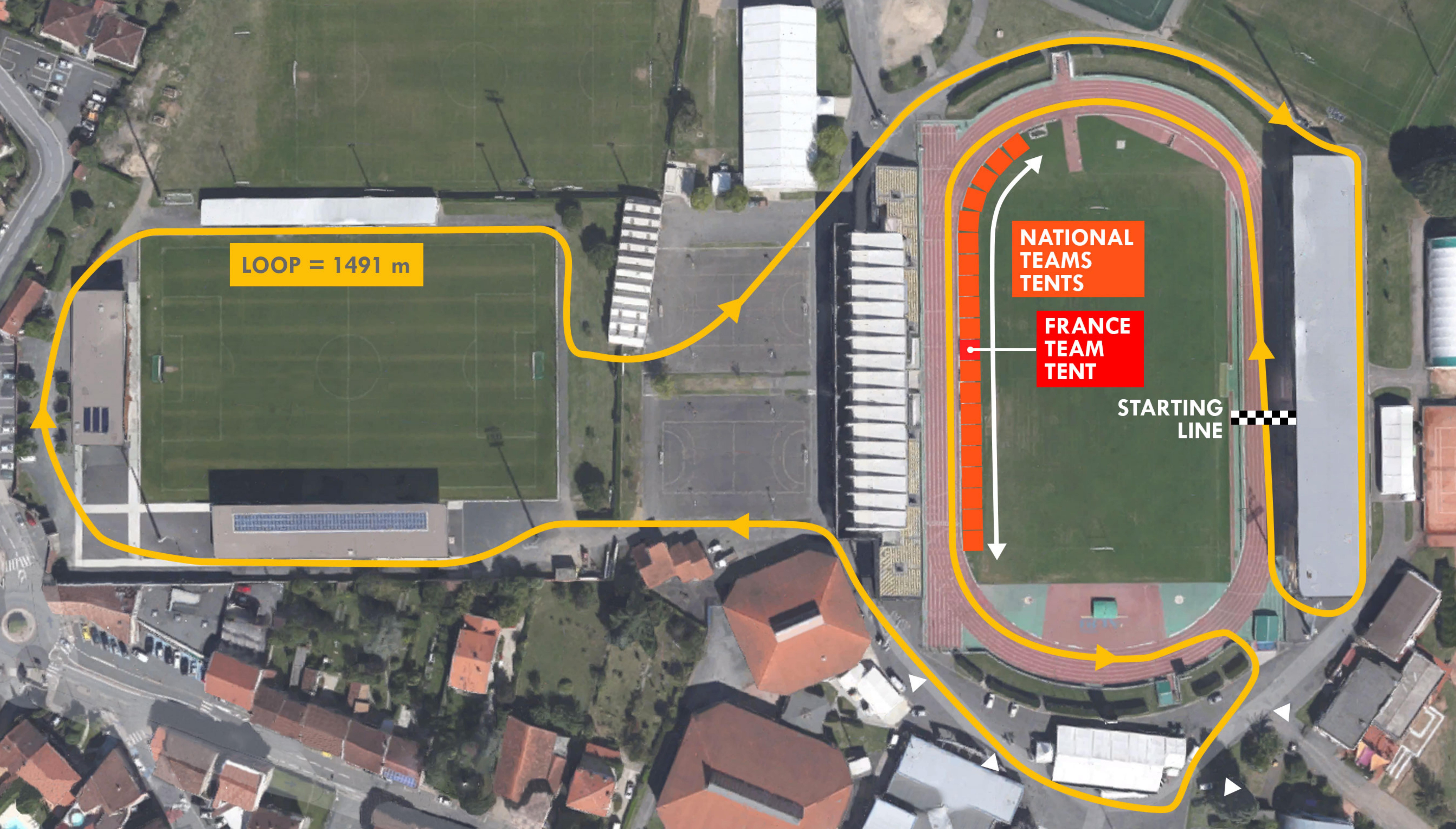



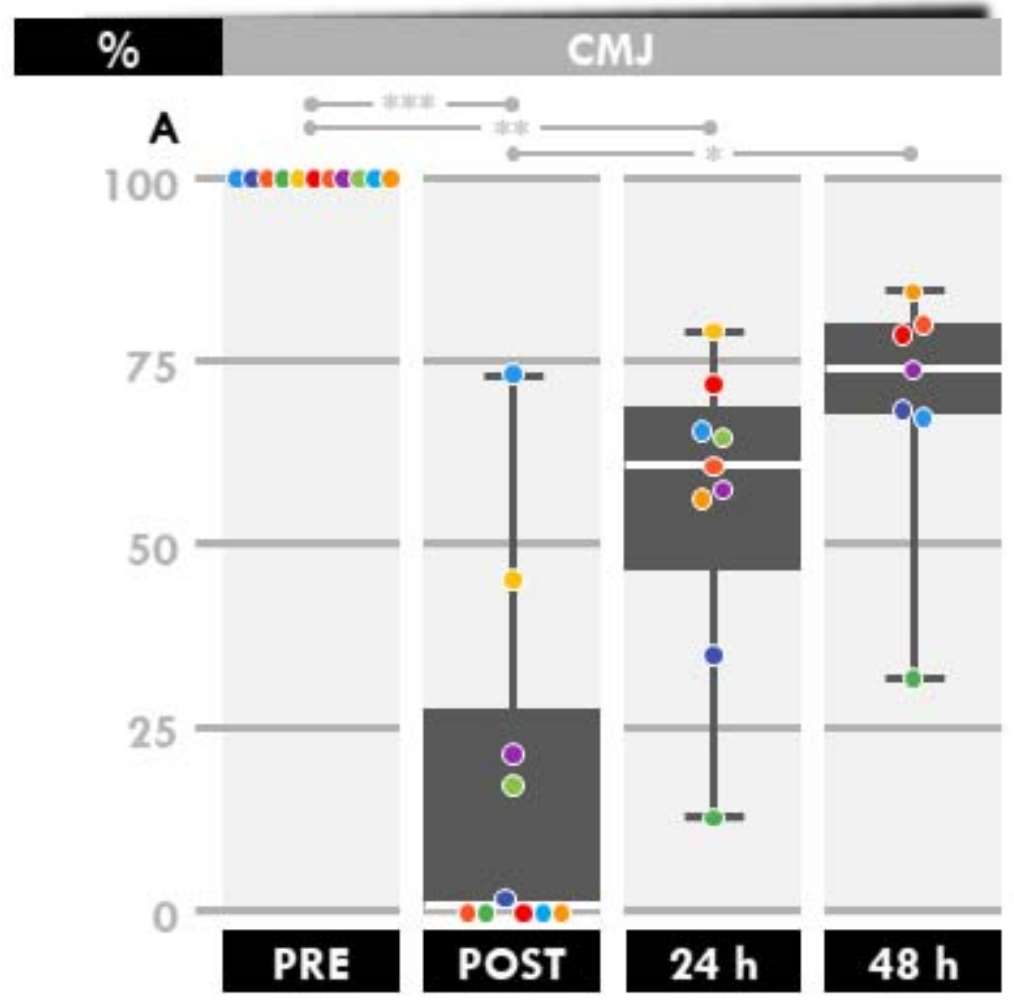

\section{$/ 100$ \\ Muscle soreness}

B

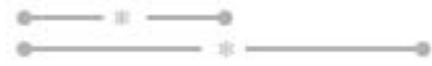

100

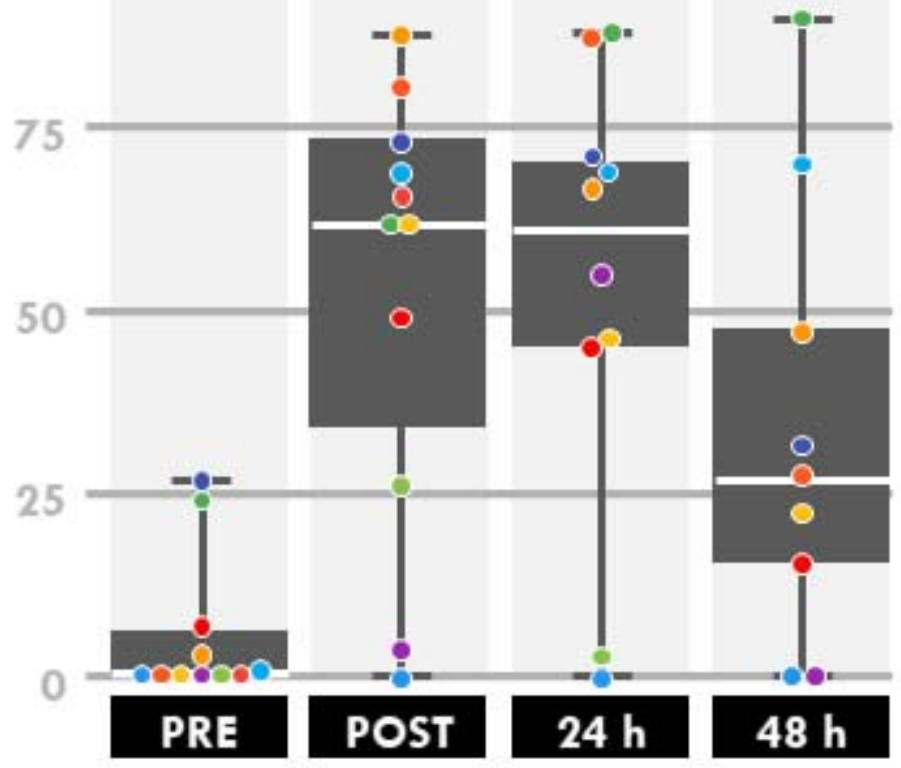



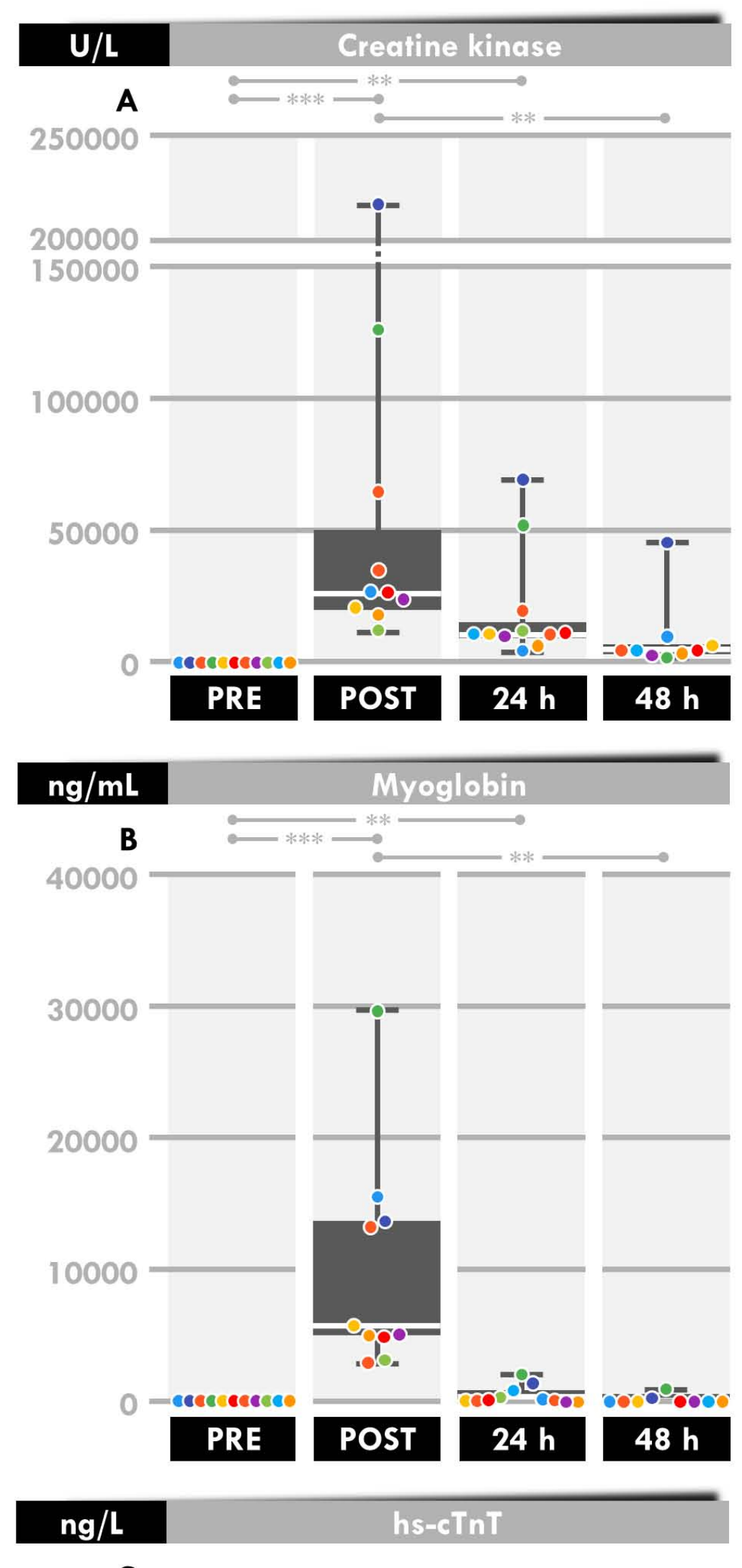

C

80

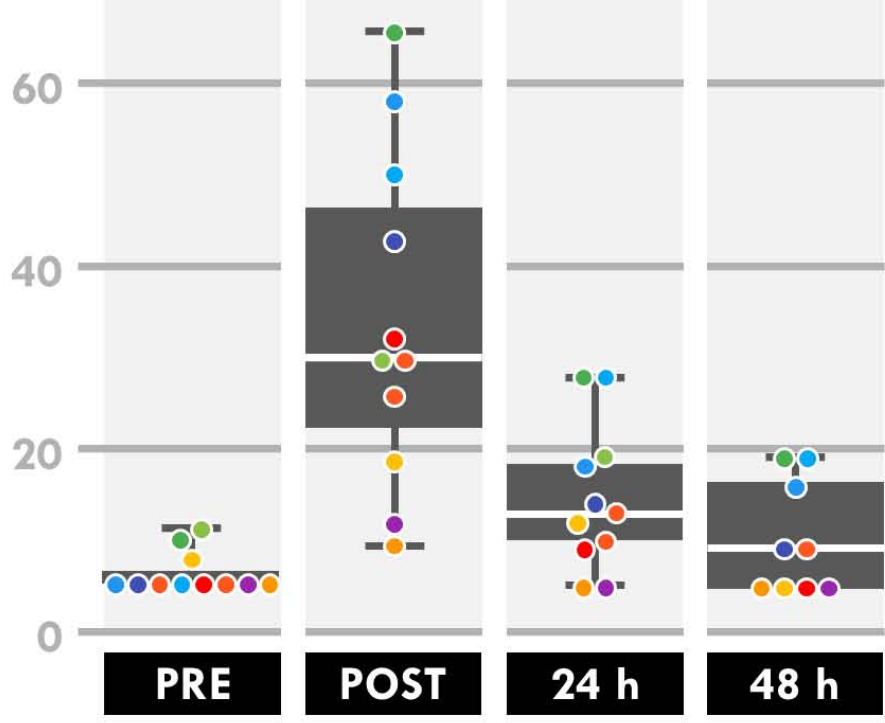


10000

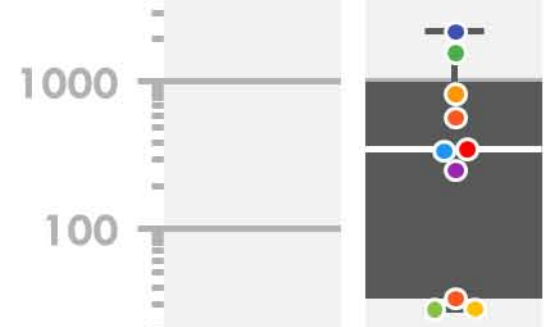

10

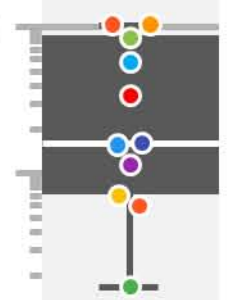

0.1
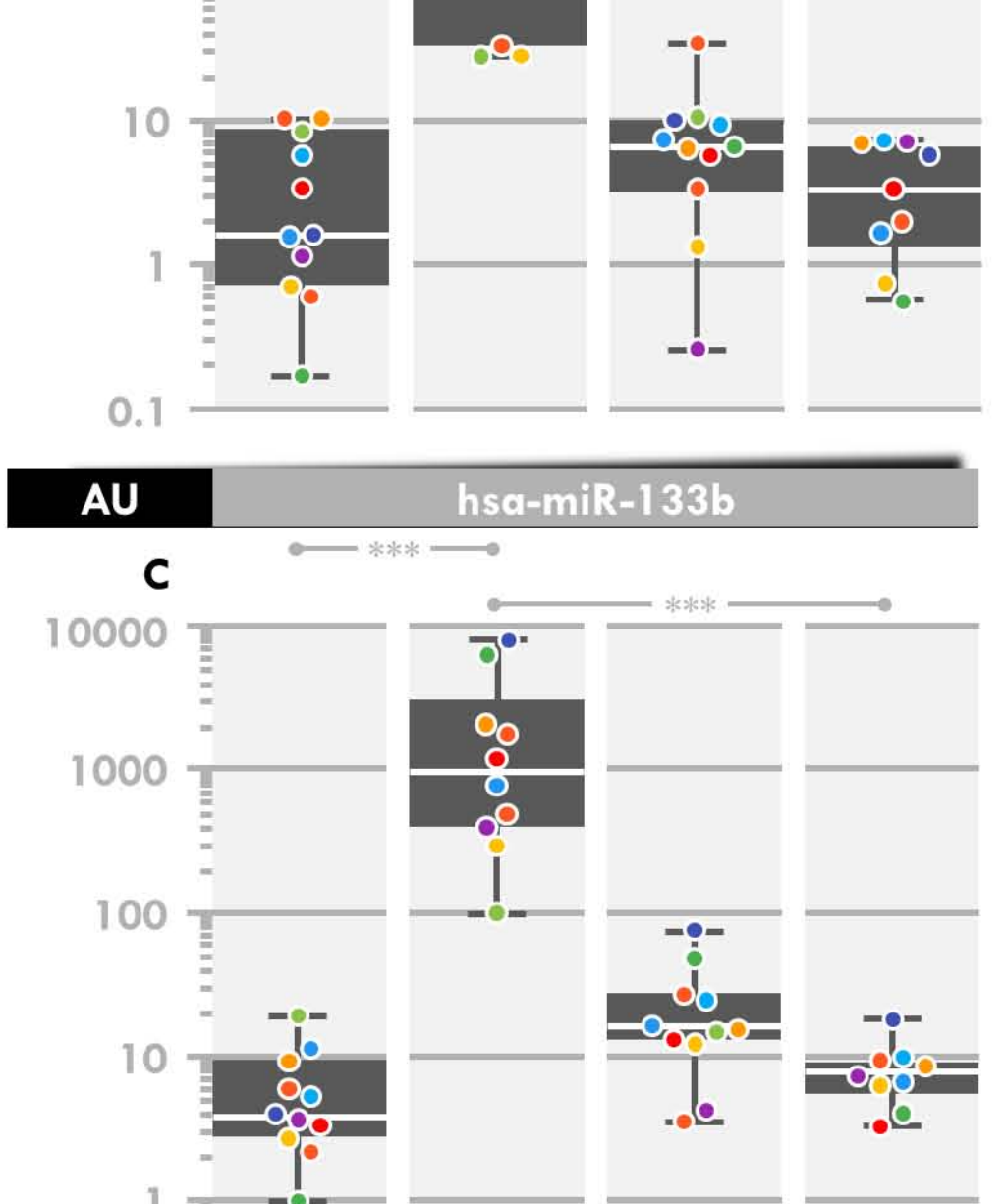

\section{1}
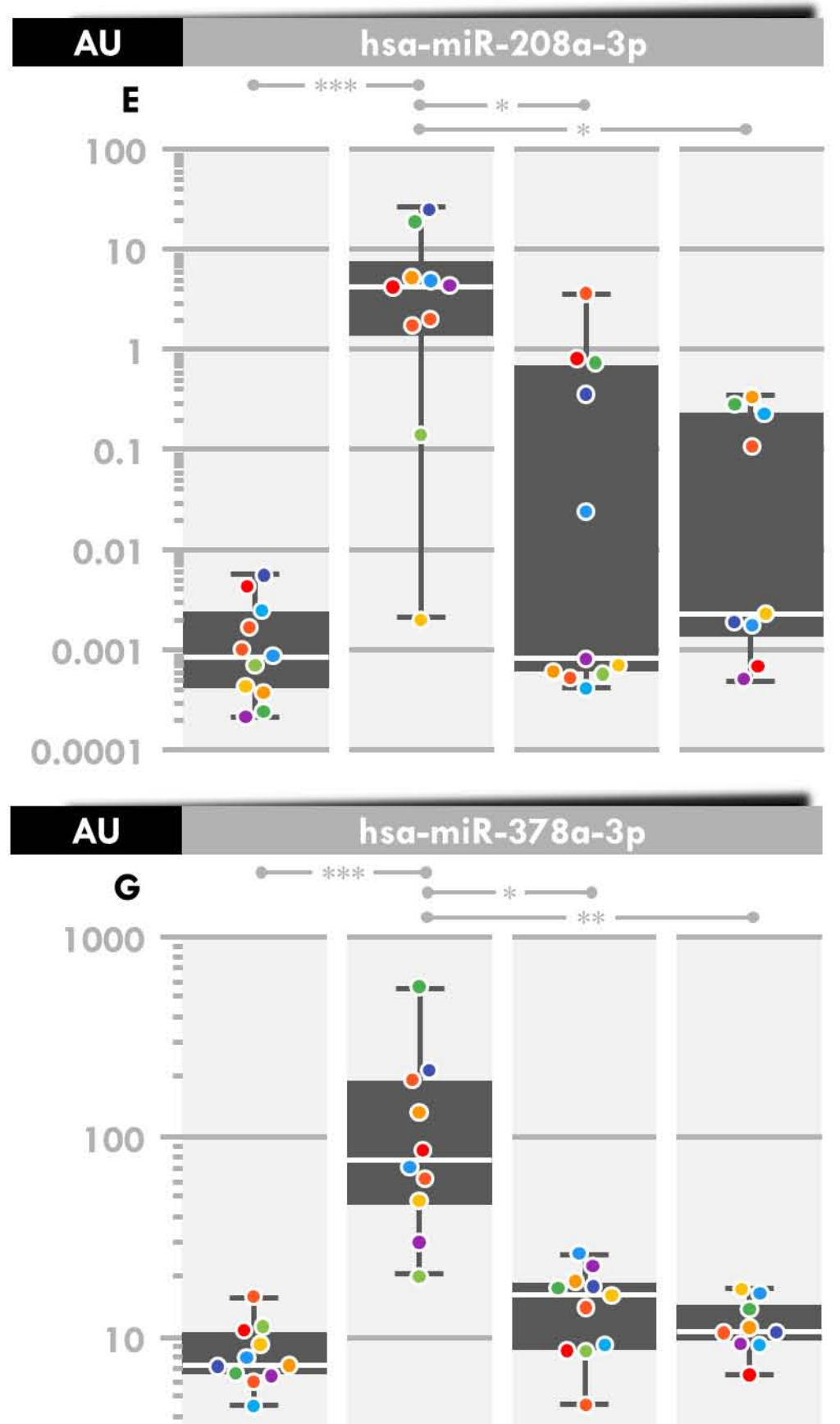

PRE

POST

$24 \mathrm{~h}$

$48 \mathrm{~h}$
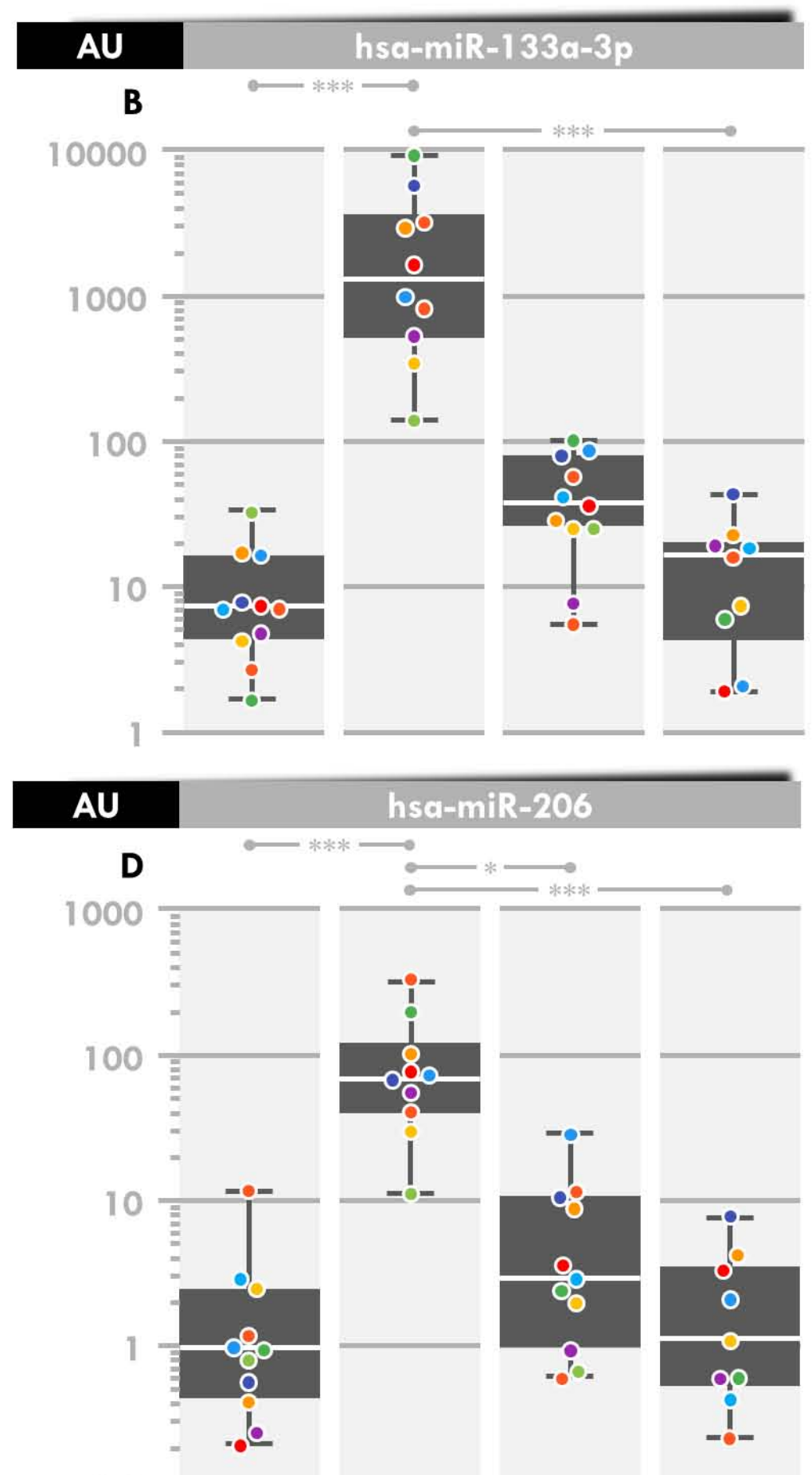

0.1
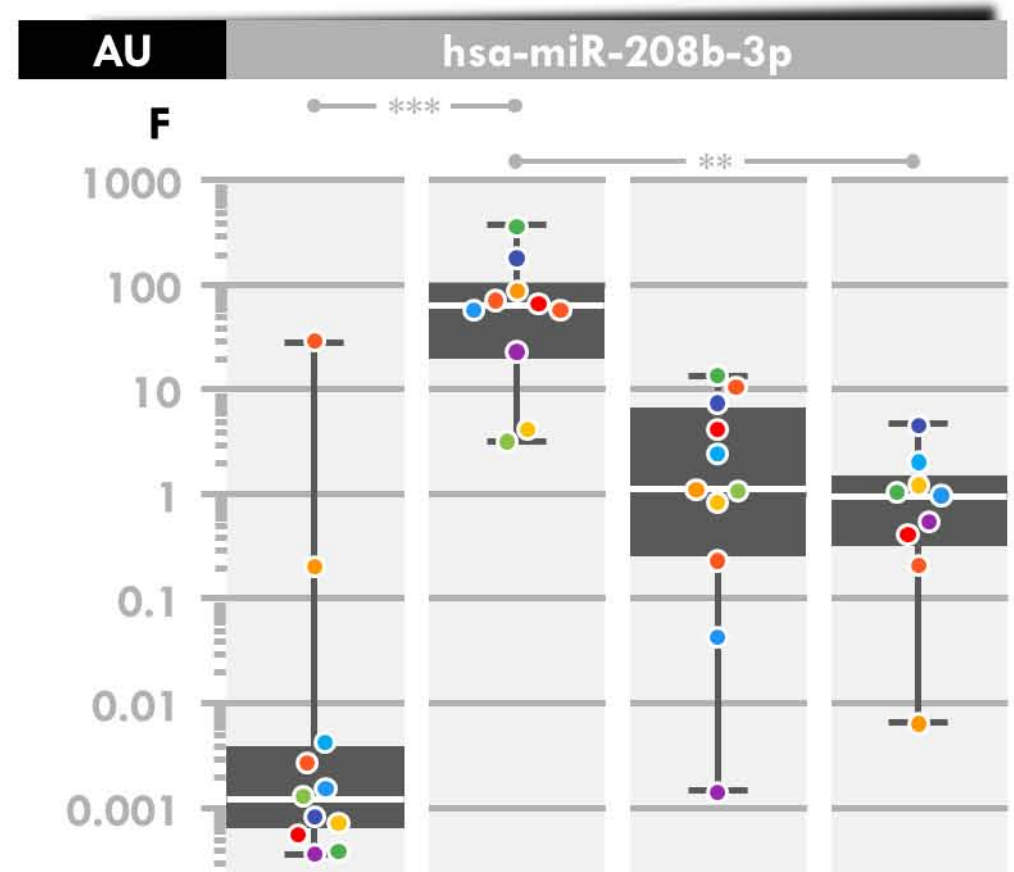

0.0001
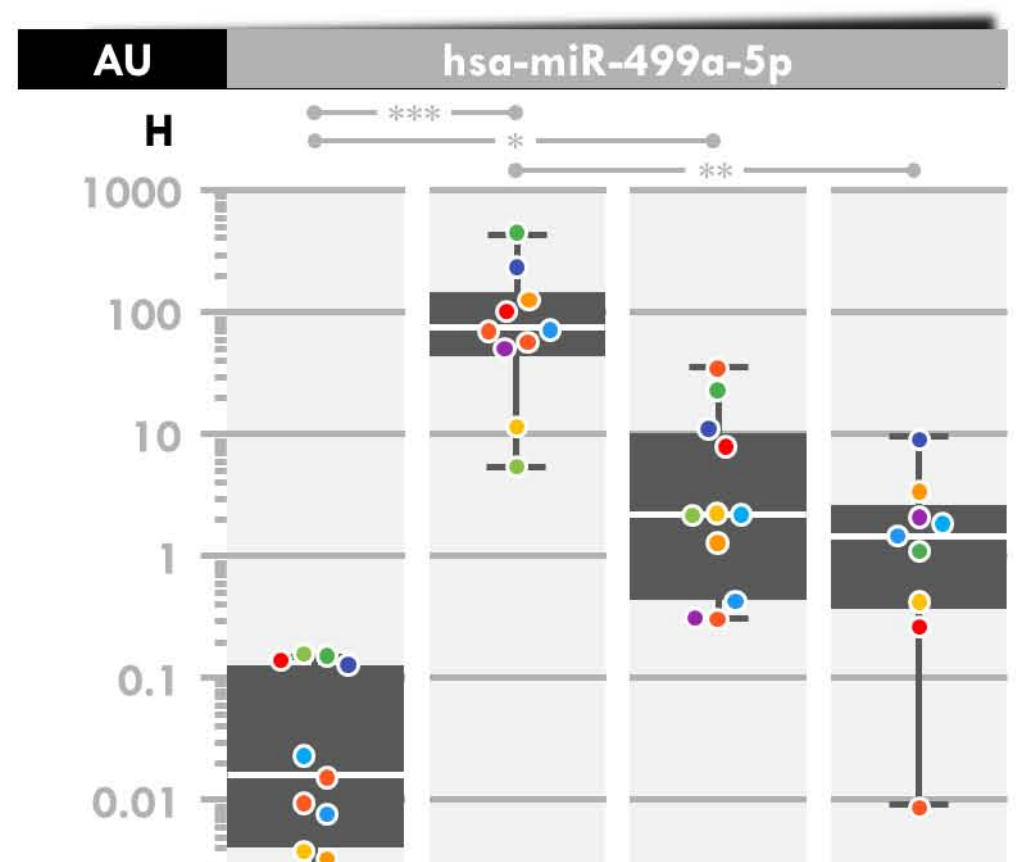

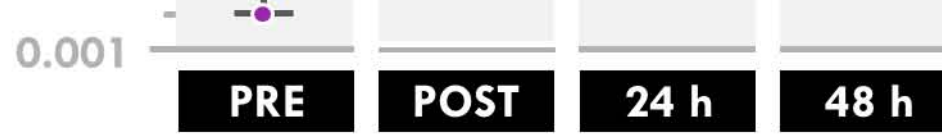



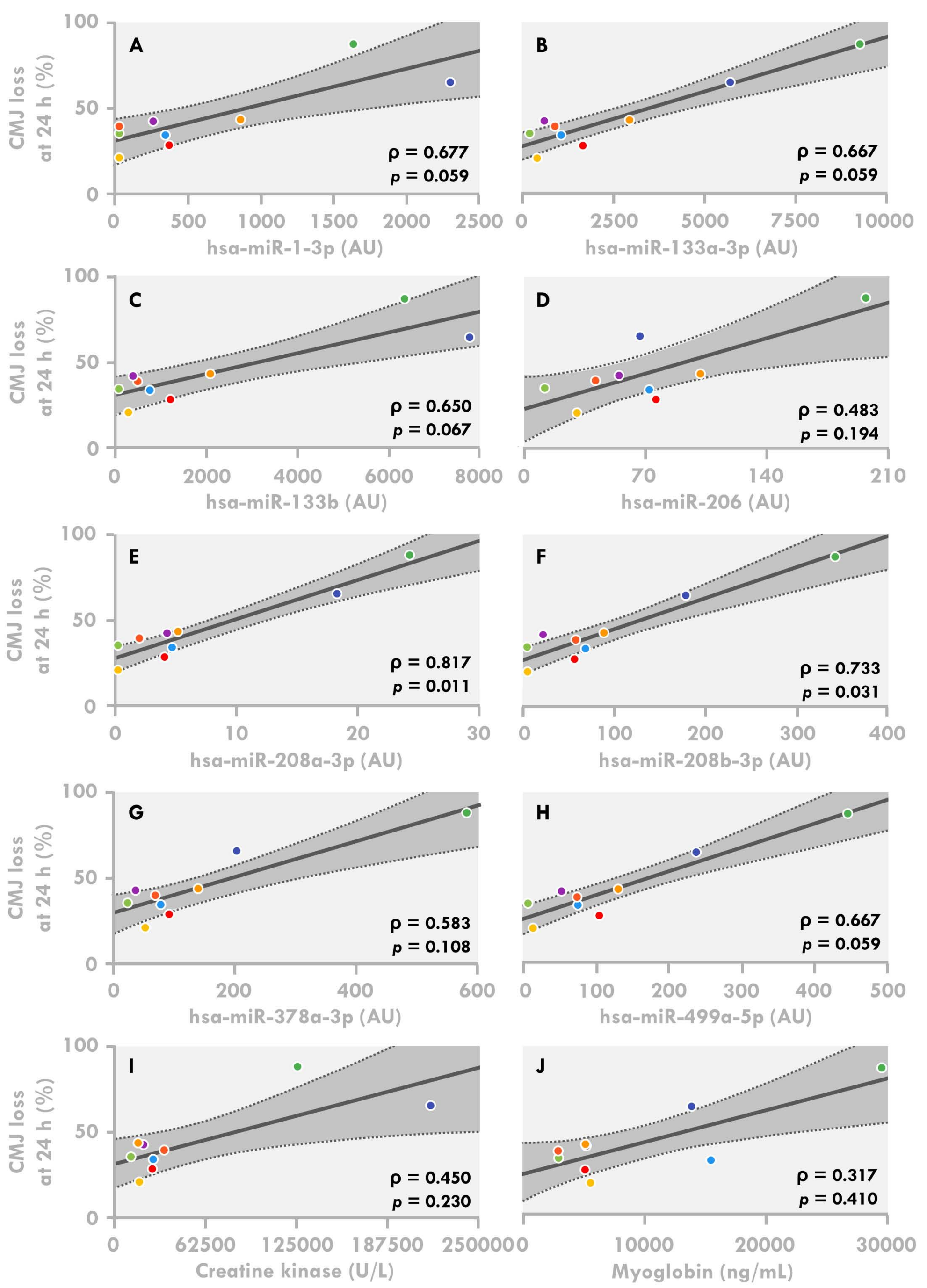